\section{Rodízio de postos em abate de bovinos: para além das dimensões físicas do trabalho}

\author{
Job rotation in beef packing operations: beyond \\ the physical dimensions of work
}

\section{Rotación de puestos en el sacrificio de bovinos: más allá de las dimensiones físicas del trabajo}

Adelaide Nascimento 1

Iracimara Anchieta de Messias 2

\title{
Resumo
}

A norma brasileira NR-36, específica para indústrias de abate e processamento de carnes, indica a necessidade de implantação de rodizios de postos para reduzir a exposição dos trabalhadores a constrangimentos físicos repetitivos e controlados por máquinas. Porém, estudos demonstram que os efeitos alcançados com essa implantação são geralmente inferiores ao esperado e que a rotação sozinha não seria a solução para os problemas de saúde no trabalho. Por meio de uma pesquisa empírica em um frigorífico de abate de bovinos, o objetivo deste artigo é apresentar e discutir dimensões do trabalho real consideradas relevantes para a saúde e segurança dos trabalhadores. Tais dimensões constituem elementos importantes a serem considerados em projetos de implantação de rodízio de postos. A metodologia compreende entrevistas coletivas com 16 trabalhadores voluntários divididos em 4 grupos. As técnicas de grupo focal e de confrontação coletiva valendo-se de filmes da atividade foram utilizadas. Os resultados evidenciam dimensões já conhecidas na literatura relacionadas aos constrangimentos físicos, competências necessárias, ritmo de trabalho e falta de tempo para realizar um trabalho de qualidade. Dados novos aparecem quanto às prescrições heterogêneas do trabalho que representam uma fonte de pressão psíquica em zonas do abate. Essas dimensões organizacionais impactam a atividade individual e coletiva dos trabalhadores, assim como a saúde no trabalho. Do nosso ponto de vista, e corroborando estudos internacionais, além das dimensões físicas do trabalho, aspetos organizacionais, humanos, estratégicos e pedagógicos devem ser considerados em projetos de implantação do rodizio de postos.

Abatedouros; Carga de Trabalho; Legislação Trabalhista; Saúde do Trabalhador

\author{
Correspondência \\ A. Nascimento \\ Conservatoire National des Arts et Métiers. \\ 41 rue Gay Lussac, Paris / Ile-de-France - 75005, France. \\ adelaide.nascimento@cnam.fr \\ 1 Conservatoire National des Arts et Métiers, Paris, France. \\ 2 Faculdade de Ciências e Tecnologia, Universidade Estadual \\ Paulista "Julio de Mesquita Filho", Presidente Prudente, Brasil.
}




\section{Introdução}

A expansão da indústria de carnes no Brasil levanta importantes questões de saúde pública. Em 2017, o país exportou em carnes bovinas o equivalente a 6,2 bilhões de dólares, alcançando um faturamento 13\% maior em relação a 2016; já em volumes do embarque foram 1.533 mil toneladas, correspondendo a um aumento de $9 \%$ no mesmo período do ano anterior ${ }^{1}$. De acordo com órgãos fiscalizadores, essa expansão tem sido responsável pelo aumento de doenças musculo-esqueléticas e acidentes de trabalho sofridos pelos trabalhadores do setor de produção 2. Estudos realizados no Brasil 3,4, mas também na França 5 , no Canadá 6,7 e Suécia 8 , apontam que os fatores de risco são inúmeros, tanto físicos (força exercida, trabalho estático e monótono, constrangimentos posturais, gestos repetitivos, postos de trabalho e equipamentos inadequados, exposições ao frio e a vibrações) quanto psicossociais (organização do trabalho, relações interpessoais, tarefas de ciclos curtos, pouca autonomia no trabalho, formação insuficiente, poucas pausas).

Com relação às doenças que acometem os trabalhadores nas indústrias de carnes, identificam-se doenças como a leptospirose, brucelose e toxoplasmose, como apresentado por Gonçalves et al. 3, e até mesmo mortalidade por câncer mais elevada do que na população em geral devido à exposição a agentes virais bovinos ${ }^{9}$. Entretanto, são as doenças musculo-esqueléticas as que mais preocupam devido à frequência elevada. Dos 800 mil funcionários de frigoríficos brasileiros, 150 mil sofrem algum tipo de desordem osteomuscular 10 .

Com base em registros de inspeções realizadas por auditores fiscais do trabalho, denúncias de sindicatos, avanços científicos e pressão política, entre outros, o Ministério do Trabalho e Emprego (MTE) regulamentou oficialmente uma norma específica para o setor de frigoríficos. Após dez anos de negociações, foi publicada em 19 de abril de 2013 a NR 36 - Segurança e Saúde no Trabalho em Empresas de Abate e Processamento de Carnes e Derivados 11. O texto enumera 15 itens principais, que vão desde mobiliário e postos de trabalho até informações e treinamentos em saúde e segurança no trabalho, estabelecendo os requisitos mínimos para avaliar, controlar e monitorar os riscos na atividade 1. Dentre as exigências, encontra-se a implantação de rodízios de postos, com o objetivo de reduzir a exposição através de "alternância de atividades, (...) entre tarefas com cadência estabelecida por máquinas, esteiras e nórias e outras tarefas em que o trabalhador possa determinar livremente seu ritmo de trabalho" (NR-36, 36.14.7.1.1) 11.

Segundo Ouellet et al. 12, o rodízio de postos é uma prática frequente no setor de frigoríficos pois é percebido como uma maneira de aumentar a polivalência dos trabalhadores e reduzir os problemas de DORT (distúrbio osteomuscular relacionado ao trabalho). O estudo de Falardeau \& Vézina 13, por exemplo, mostra que tanto os encarregados quanto os trabalhadores são favoráveis à rotação de postos em um frigorífico de abate e processamento de porcos. Uma intervenção ergonômica realizada por Barth \& Guimarães 14 indica que os trabalhadores de um frigorífico de aves relatam menos dores e desconfortos após a implantação do rodízio de postos. No entanto, alguns estudos demonstram que os efeitos alcançados com essa implantação são geralmente inferiores ao esperado e que a rotação sozinha não seria a solução para os problemas de DORT 15,16,17. Na realidade, as condições nas quais se realiza a implantação do rodízio são determinantes para o sucesso ou fracasso da rotação 18 .

Dentre os aspectos a serem considerados, encontramos dificuldade de adaptar os postos de trabalho às diferentes morfologias, a exposição dos trabalhadores a constrangimentos físicos e estresse, e a aprendizagem de uma nova tarefa ${ }^{12}$. Com efeito, as tarefas que necessitam de rotação estão em linhas de produção com uma forte especialização e divisão do trabalho, o que demanda tempo para a realização de treinamento e o desenvolvimento de competências. Assim, uma redução da produtividade pode ser percebida em um primeiro momento de aprendizagem e deve ser levada em conta pela hierarquia 19. No entanto, essa redução nem sempre significa perda de qualidade. Coutarel et al. 5 indicam condições materiais, organizacionais, humanas, estratégicas e pedagógicas para que o rodízio seja implantado de maneira eficaz. Em um frigorífico estudado, reduzindo a produção de 1.050 para 600 patos abatidos por hora e treinando os trabalhadores para o rodízio, eles conseguiram um equilíbrio entre saúde e desempenho: aumentar o peso da carne vendida e reduzir o absenteísmo.

A NR-36 menciona que o rodízio deve ser definido pelos profissionais do Serviço Especializado em Engenharia de Segurança e em Medicina do Trabalho (SESMT) e implantado com a participação da Comissão Interna de Prevenção de Acidentes (CIPA) e dos trabalhadores envolvidos. Nesse 
sentido, uma etapa preliminar à implantação consiste em organizar a participação dos trabalhadores para que eles possam se expressar sobre o assunto.

Sabendo-se que não existe um consenso na literatura internacional com relação aos benefícios efetivos da rotação de postos de trabalho e que poucos estudos tratam da questão na literatura brasileira, este artigo visa a colaborar com o debate nacional sobre a questão, nomeadamente no recente contexto legislativo vigente. Utilizando-se de uma pesquisa empírica em um frigorífico de abate de bovinos, o objetivo deste artigo é apresentar e discutir dimensões do trabalho real consideradas relevantes para a saúde e segurança dos trabalhadores. Tais dimensões constituem elementos importantes a serem considerados em projetos de implantação de rodízio de postos.

A pesquisa se insere no campo teórico da ergonomia da atividade 20 , no qual o trabalhador não é visto como aquele que executa uma tarefa, mas como o criador de sua própria mobilização, articulando no contexto de seu trabalho os requisitos da tarefa, a vontade de se preservar, de ter sucesso e de aprender, regulando sua atividade em relação aos resultados que ela produz, tanto do ponto de vista dos objetivos da tarefa como dos seus efeitos sobre ele mesmo e sobre o coletivo 21,22 .

\section{Métodos}

Os dados apresentados neste artigo correspondem a uma parte da pesquisa intitulada Da Análise à Ação Ergonômica em Frigoríficos: Concepção Participativa de Rodízios no Setor de Abate, realizada em um frigorífico de grande porte localizado na Região Oeste do Estado de São Paulo, Brasil. A pesquisa-ação parte de uma demanda da empresa relacionada à implantação de rodízio no setor de abates, face à exigência da NR-36. Após análise da demanda, a etapa de reformulação consistiu em propor um projeto de concepção participativa no qual a implantação do rodízio será discutida com os atores sociais da empresa, após uma fase de diagnóstico oriunda da análise ergonômica do trabalho. Nesse sentido, foi criado na empresa um comitê de ergonomia com a participação de profissionais do SESMT, de um representante da CIPA, do gestor de RH e das duas pesquisadoras. A participação dos trabalhadores do abate foi feita por meio de entrevistas coletivas e grupos de trabalho.

A fim de responder aos objetivos deste artigo, foram selecionados os dados relativos às entrevistas coletivas, inspiradas em técnicas de grupo focal 23,24 e de confrontação coletiva 25,26.

\section{Contexto e população}

A empresa estudada tem 600 trabalhadores em seu quadro de funcionários, dentre os quais, 70\% encontram-se nos setores produtivos de abate, desossa e condicionamento. A população pesquisada corresponde ao pessoal do setor de abate de bovinos, escolhida para a realização de um projeto piloto sobre a implantação do rodízio. Dos 81 trabalhadores do setor, 9 são considerados novatos (menos de um ano de experiência). Cerca de $2 / 3$ da população têm mais de 40 anos, sendo que 74 são homens e 7 são mulheres. Os trabalhadores são especializados nas funções que ocupam na linha de produção.

Existem duas zonas de trabalho no abate: área suja (abate, retirada do couro e serragem do peito) e área limpa (corte da carcaça, retirada da cabeça e das vísceras, e limpeza). Cerca de 600 bois são abatidos por dia, correspondendo a uma velocidade da nória entre 90 e $120 \mathrm{~m} / \mathrm{h}$.

\section{Coleta e análise de dados das entrevistas coletivas}

O recrutamento dos participantes foi realizado durante as fases de observação do trabalho no setor de abate, no qual os observados foram questionados sobre o interesse em participar do projeto. No total, 16 trabalhadores se apresentaram como voluntários ( 7 da área suja e 9 da área limpa, sendo 3 mulheres e 13 homens) e foram distribuídos em quatro grupos de 4, 6, 2 e 4 trabalhadores cada. O critério de repartição foi a proximidade funcional na linha de produção, de maneira a facilitar o acesso ao trabalho coletivo e às diferentes exigências da tarefa em função da zona de trabalho. Os participantes são apresentados na Tabela 1. Eles são experientes na função (mais de um ano) e com idades entre 33 e 65 anos. Quatro entrevistas coletivas foram realizadas entre 31 de agosto e 7 de novembro de 2016, correspondendo a uma entrevista por grupo. As entrevistas coletivas duraram aproximadamente 40 
Tabela 1

Perfil demográfico dos participantes de acordo com a área de trabalho.

\begin{tabular}{|c|c|c|c|c|}
\hline $\begin{array}{l}\text { Área de trabalho/ } \\
\text { Trabalhador(a), entrevista }\end{array}$ & Função & $\begin{array}{c}\text { Experiência em frigoríficos } \\
\text { (anos) }\end{array}$ & Sexo & Idade (anos) \\
\hline \multicolumn{5}{|l|}{ Área suja } \\
\hline T1, E4 & Magarefe "B" & 13 & Masculino & 43 \\
\hline $\mathrm{T} 2, \mathrm{E} 3$ & Magarefe " $C$ " & 13 & Masculino & 65 \\
\hline T3, E2 & Faqueiro “B” & 5 & Masculino & 28 \\
\hline $\mathrm{T} 4, \mathrm{E} 2$ & Magarefe "A" & 15 & Masculino & 52 \\
\hline $\mathrm{T} 5, \mathrm{E} 2$ & Faqueiro " $\mathrm{A}$ " & 16 & Masculino & 50 \\
\hline T6, E2 & Magarefe "A" & 9 & Masculino & 42 \\
\hline T7, E2 & Faqueiro "C" & 16 & Masculino & 58 \\
\hline \multicolumn{5}{|l|}{ Área limpa } \\
\hline T8, E4 & Faqueiro “B” & 9 & Masculino & 33 \\
\hline T9, E4 & Supervisor de equipamentos & 15 & Masculino & 54 \\
\hline T10, E4 & Magarefe "A" & 15 & Masculino & 45 \\
\hline T11, E3 & Magarefe "A" & 3 & Masculino & 44 \\
\hline $\mathrm{T} 12, \mathrm{E} 1$ & Assistente de balança & 9 & Feminino & 43 \\
\hline $\mathrm{T} 13, \mathrm{E} 1$ & Magarefe " $A$ " & 11 & Masculino & 45 \\
\hline T14, E1 & Auxiliar de linha de produção & 15 & Feminino & 54 \\
\hline T15, E1 & Magarefe " $\mathrm{C}$ " & 5 & Masculino & 56 \\
\hline T16, E2 & Refilador "A" & 2 & Feminino & 40 \\
\hline
\end{tabular}

minutos. Foram realizadas na mesma sala de reunião, no âmbito da empresa, após o fim da jornada de trabalho. Não havia representantes da empresa nos grupos. Os trabalhadores se expressaram livremente, sem hesitações, expondo como são desenvolvidas suas atividades, discutindo coletivamente dificuldades de suas jornadas de trabalho.

As entrevistas coletivas realizadas combinaram duas técnicas complementares:

(1) A técnica do grupo focal, "caracterizada como uma técnica de investigação de coleta de dados através da interação do grupo sobre um tópico apresentado pelo investigador” 23 (p. 130). Nesta pesquisa, o tópico apresentado foi o projeto de realização do rodízio no setor de abate, focalizando a discussão nas competências para ocupar um posto. Após explicação sobre os objetivos da pesquisa, o papel dos investigadores consistiu em moderar o grupo, considerando os seguintes itens: (i) uma lista de questões preparadas previamente (“Em que consiste o trabalho no abate?”; "Quais as competências necessárias para trabalhar no abate?”; "Se eu tivesse de começar hoje o trabalho no abate, o que é que eu deveria saber?”); (ii) questões emergentes de acordo com as respostas do grupo; e (iii) assegurando que todos os presentes participassem da discussão. Essa técnica foi utilizada durante a primeira parte da entrevista coletiva.

(2) A técnica de confrontação coletiva é caracterizada pela utilização de traços da atividade de trabalho como objeto da discussão coletiva 25,26 . Na nossa pesquisa, os traços da atividade de trabalho foram filmes da atividade realizados durante a etapa de observação no setor de abate. Durante as entrevistas coletivas, os filmes referentes aos trabalhadores presentes foram exibidos ao grupo com o objetivo de compreender melhor o que está em jogo na situação de trabalho singular. A lista de questões preparadas previamente é a seguinte: "Você poderia me explicar o que você está fazendo?"; "Outro trabalhador do abate poderia fazer o mesmo?”; "Quais as dificuldades de realizar esse trabalho?”; "Qual o impacto do que você faz no trabalho dos outros?"; "Qual o impacto do trabalho dos outros no que você faz?”. O papel dos investigadores consistiu em favorecer a confrontação das práticas de trabalho e fazer emergir os aspectos coletivos do trabalho em linha de produção. Essa técnica foi utilizada durante a segunda parte da entrevista coletiva. 
As entrevistas foram filmadas e os dados obtidos foram transcritos. A análise dos dados foi feita seguindo as seguintes etapas, de acordo com Silva et al. 24 e Fontanella et al. 27: (i) Codificação (leitura dos textos e atribuição de categorias de acordo com os temas da lista de questões emergentes); (ii) Recuperação (digitação em uma planilha Excel [Microsoft Corp.] dos extratos de texto subordinados a mesma categoria); (iii) Recodificação (releitura e atribuição de subcategorias, fusão de categorias, criação ou supressão de categorias); e (iv) Interpretação (análise sistemática dos dados). A Tabela 2 apresenta as categorias e subcategorias de codificação de acordo com o grupo e a área de trabalho (suja ou limpa).

A realização da pesquisa teve aprovação do Comitê de Ética em Pesquisa com Seres Humanos da Faculdade de Ciências e Tecnologia, Universidade Estadual Paulista "Julio de Mesquita Filho" (CAAE no 24268713.0.0000.5402), de acordo com a Resolução no 196/1996 do Conselho Nacional de Saúde.

\section{Resultados}

A maioria dos trabalhadores entrevistados não se mostrou contrária ao rodízio de postos, que foi aceito por 11 deles. A priori, esses trabalhadores veem no rodízio uma possibilidade de aprendizado e de ruptura da monotonia. Os que se manifestaram contra enunciaram dificuldades ligadas ao trabalho coletivo e à remuneração. Todos os trabalhadores, sejam eles contra ou a favor do rodízio, externaram preocupações quanto à sua implantação, evidenciando dimensões relevantes do trabalho real a serem consideradas. Além do trabalho coletivo, essas dimensões compreendem as competências, o ritmo de trabalho e as fontes de prescrição contraditórias.

\section{Competências para executar as tarefas: "não é só passar a faca"}

Quando questionados sobre quais as competências necessárias para trabalhar no abate, todos os trabalhadores se referiram primeiramente ao uso das ferramentas (faca ou serra). "Parece que ali é fácil,

\section{Tabela 2}

Temas abordados nas entrevistas de acordo com a área de trabalho.

\begin{tabular}{|c|c|c|c|c|c|c|c|}
\hline \multirow[t]{2}{*}{ Temas } & \multirow{2}{*}{$\begin{array}{c}\text { E1 } \\
\text { Área limpa }\end{array}$} & \multicolumn{2}{|c|}{ E2 } & \multicolumn{2}{|c|}{ E3 } & \multicolumn{2}{|c|}{ E4 } \\
\hline & & Área limpa & Área suja & Área limpa & Área suja & Área limpa & Área suja \\
\hline \multicolumn{8}{|l|}{ Competências para executar as tarefas } \\
\hline Saber usar e amolar as ferramentas & $x$ & $x$ & $x$ & $x$ & $x$ & $x$ & $x$ \\
\hline Conhecer as normas de higiene & $x$ & $x$ & $x$ & $x$ & $x$ & $x$ & $x$ \\
\hline Garantir a qualidade do corte da carne & $x$ & $x$ & $x$ & $x$ & $x$ & $x$ & $x$ \\
\hline Prevenir acidentes & & & & $x$ & $x$ & $x$ & \\
\hline \multicolumn{8}{|l|}{ Ritmo de trabalho } \\
\hline Velocidade da nória & $x$ & $x$ & $x$ & $x$ & $x$ & $x$ & $x$ \\
\hline Tipo de boiada & $x$ & $x$ & & $x$ & & $x$ & \\
\hline Qualidade das ferramentas & & $x$ & & $x$ & & & $x$ \\
\hline \multicolumn{8}{|l|}{ Fontes de prescrição } \\
\hline Empresa & $x$ & $x$ & $x$ & $x$ & $x$ & $x$ & $x$ \\
\hline Pecuarista & $x$ & & & & & & \\
\hline Curtume & & & $x$ & & & & \\
\hline \multicolumn{8}{|l|}{ Trabalho coletivo } \\
\hline Impacto na produção & $x$ & $x$ & $x$ & $x$ & $x$ & $x$ & $x$ \\
\hline Impacto na gratificação & & & $x$ & & & & \\
\hline
\end{tabular}


mas você faz muita força para serrar o boi. E é rápido, se você não souber serrar, ele vai embora” (T1, E4, AS). É preciso saber amolar o material para que ele seja o mais eficiente possível, pois uma ferramenta bem amolada garante uma menor força na execução do corte e um corte de qualidade. "Você tem que saber amolar a sua faca. Porque se você for lá aonde eu fico e não conseguir amolar a faca, você não consegue. Porque com a faca cega não vai conseguir cortar nada, eu só entrei direto porque já sabia amolar faca, porque se não eles me encaminhariam para outro setor" (T16, E2, AL). A variabilidade da boiada é um dos determinantes para a frequência de amolação da faca. "Depende muito da qualidade da carne. Se for molinha corta fácil, se não tem que amolar toda hora a faca. A cada duas ou três peças a gente afia para a faca não perder seu corte" (T4, E2, AS).

O uso da faca é associado ao conhecimento das normas de higiene. Para evitar riscos de contaminação entre os bois, a faca deve ser trocada e lavada a cada carcaça cortada, para fins de esterilização. Um monitor é responsável pela fiscalização das regras de higiene. As facas apresentam cabos de cores diferentes para facilitar a fiscalização. "São normas que a empresa alimentícia tem que seguir, tem que fazer essa troca por causa da contaminação, evita contaminar, enquanto uma está sendo usada a outra estará sendo esterilizada" (T14, E1, AL). Todos os trabalhadores conhecem as regras de higiene, mas questionam sua aplicação devido à falta de tempo. "A troca das facas, fazemos conforme dá, né? Quando dá tempo. O certo seria fazer uma carcaça, trocar e fazer outra, mas na realidade, a gente não consegue fazer, então conforme dá" (T12, E1, AL). "A monitora falou que teria que usar 3 facas em um mesmo boi. Trinta segundos por boi, e teria que usar três facas! Para começar eu vou colocar bem devagarzinho a faca, senão ela perde o corte. Eu teria que furar a medula com a faca azul, abrir o boi com a faca amarela, quer dizer, isso é impossível, não tem como" (T13, E1, AL).

Outra competência determinante para executar a tarefa no abate evocada em todos os grupos é a garantia da qualidade do corte da carne. Os trabalhadores são exigentes quanto a esse aspecto. "Não é só passar a faca. Fomos treinados para qualidade do serviço" (T9, E4, AL). “Aí [apontando para o filme] eu não estou fazendo força com a serra. Isso para carcaça sair bonita, não ficar entrando de um lado e outro, para não afundar a carne do contra file”" (T11, E3, AL). "Me preocupo por que é a minha profissão e eu não posso fazer errado" (T1, E4, AS). Eles enfatizam que tais habilidades necessitam de tempo de aprendizagem. "Pega o jeito devagar, porque o trabalho não é de uma hora para outra que nem, por exemplo, como realizar o trabalho com uma enxada. Enquanto não pegar o jeito não vai” (T2, E3, AS).

Em dois grupos (E3 e E4), os trabalhadores mencionaram além dessas competências a necessidade de saber prevenir os acidentes de trabalho. São trabalhadores que usam a serra elétrica em plataformas pneumáticas ou o correntão para a retirada do couro do boi. No primeiro caso, o risco de choque elétrico é evidenciado assim como a importância de preveni-lo e identificá-lo desde as primeiras sensações de descarga elétrica. "Já aconteceu em outra empresa, teve um cara que morreu por causa de um choque. O fio estava desencapado. Aqui, teve um dia que eu saí à tarde e falei para o eletricista: dá uma olhada lá, que nos últimos três bois que eu cortei eu senti que passou um choque de leve na minha mão" (T11, E3, AL). $\mathrm{O}$ risco de corte com a serra também é mencionado. No correntão, a estratégia encontrada pelo trabalhador para evitar a queda do boi, quando o couro é retirado, é enlaçar o couro em forma de nó e afundar o pescoço do boi com uma faca. "A um novato eu iria ensinar a preparar a enlaçada do couro, para amarrar certinho para não escapar e assinalar a botoeira até chegar no normal, certo? Porque se não ele estará aéreo rodando, e se escapar tem que parar a nória" (T2, E3, AS).

\section{Ritmo de trabalho: "se parou, o sangue esfria"}

O ritmo de trabalho no abate é determinado em grande parte pela cadência da nória, ganchos onde são pendurados os bois e carcaças que se deslocam na linha de produção a uma velocidade constante regulada pelo encarregado da produção. Ela varia de $90 \mathrm{~m} / \mathrm{h}$ em dias de vistorias do MTE ou visitas de clientes na empresa a $120 \mathrm{~m} / \mathrm{h}$ em dias normais. "A única diferença é quando tem auditoria, que eles veem os mínimos detalhes operacionais, aí eles colocam $90 \mathrm{~m} / \mathrm{h}$. É a única mudança quando tem vistoria do ministério" (T1, E1, AL). Observamos um ritmo de 3 a 4 carcaças por minuto. Os movimentos devem ser precisos e rítmicos, requerendo uma sintonia obrigatória entre os trabalhadores e as máquinas. Eles devem acompanhar o ritmo constante (mas nem sempre regular devido às pausas por falta de energia ou recuperação de erros), ao mesmo tempo em que respeitar as regras de higiene e de qualidade. Essas exigências face à velocidade acelerada da nória conduzem a arbitragens como visto no ponto anterior: 
esterilizar, trocar e amolar a faca quando dá. "Porque na verdade isso é exigido pelo controle de qualidade e pelo gerente, só que para cumprir isso é complicado, a não ser quando tem auditoria a $90 \mathrm{~m} / \mathrm{h}$ que está bem manso, suave. Aí se tem tempo de fazer troca normal, mas na velocidade de 120 $/ \mathrm{h}$ não dá" (T1, E1, AL).

Quando questionados sobre a velocidade ideal da nória, do ponto de vista do trabalho a ser realizado, os trabalhadores de todos os grupos explicaram que uma velocidade mais baixa comporta pelo menos dois inconvenientes: o cansaço e o sono devido ao ritmo de trabalho mais lento e o risco de terminar a jornada de trabalho mais tarde. "O ideal é $120,110 \mathrm{~m} / \mathrm{h}$. Pode tocar o dia inteiro, porque se parou, o sangue esfria. Aí vai ter que aquecer" (T14, E1, AL). "Nória lenta dá a impressão que não se desenvolve, aí o corpo fica mole. Dá sono porque você tem que parar” (T16, E2, AL). Além de ser uma estratégia para vencer a monotonia, um ritmo mais acelerado é a garantia de trabalhar por menos tempo e ganhar mais tempo para a recuperação da fadiga, já que a jornada de trabalho varia de acordo com o número de bois a serem abatidos. "Aquela intuição de que acabou vai embora, por exemplo. Então quanto mais rápido andar mais tempo temos para descansar mais cedo. Quando vai devagarinho, se era para acabar às 2 horas acaba 4, 5 horas" (T16, E2, AL). É interessante perceber que a redução do número de bois abatidos (600 atualmente) não se reflete em uma escolha organizacional de redução da intensidade de trabalho. "Antigamente aqui matava em média 850 bois por dia, 80 por hora. A gente ultrapassava o nosso horário de trabalho. Então seria ruim para a gente e para a empresa. Não renderia” (T12, E1, AL).

Saber acompanhar o ritmo acelerado da nória torna-se assim um pré-requisito implícito para poder executar funções no abate. "Aí, pode matar 200 bois por hora que eu dou conta. Igual um amigo meu, sexta feira matou 130 por hora. Mas ele é bom. Aí, se for outro, para toda hora, não dá conta, vai embora sem serrar" (T10, E4, AS).

Para poder acompanhar o ritmo da produção e manter as exigências de qualidade, as condições das ferramentas são fundamentais para a saúde e a produtividade. "Se a serra for boa, aí a gente vai para frente. Às vezes a gente está contente, aí quebra e você sabe que vai pegar uma serra, uma ferramenta que você sabe que vai passar raiva. Aí você já trabalhou o dia inteiro nervoso, porque você teve que fazer a maior força. E às vezes, eu que ainda sou profissional, o boi passa sem serrar porque a serra não ajuda, não dá tempo" (T10, E4, AS).

O tipo da boiada aparece também como um fator que influencia o tempo que se leva para realizar as tarefas de corte, assim como a força a ser realizada ou a quantidade de gordura a ser retirada. Esse fator é citado pelos trabalhadores da área limpa. "Vai do tratamento do gado não só da raça, alguns são tratados no pasto e outros no confinamento. $O$ de pasto o couro é mais solto, o do confinamento fica uma gordura porque ele engorda mais rápido" (T16, E2, AL). Os trabalhadores identificam variações na consistência da carne e no volume de água contido nos órgãos segundo o tipo de criação, o que dificulta o serviço com alguns tipos de bois. "Depende da boiada, não é todo boi que é igual não. Você olha ali e parece tudo igual, mas para fazer o serviço, depende da boiada. Se é mais macio ou se é mais duro, se é maior... Se bater uma faca ali, vixi... sai aquela água de fora. Aí tem que ter mais cuidado ainda para não contaminar" (T10, E4, AL).

\section{Fontes de prescrição: "aqui é mais o psicológico"}

Foram identificadas três fontes de prescrição do trabalho na empresa, uma formal e duas informais. A primeira é a própria empresa que de maneira clássica formula regras de organização da produção e de execução das tarefas. Como visto anteriormente, os trabalhadores de todos os grupos conhecem tais regras, mesmo que nem sempre possam aplicá-las como gostariam ou deveriam. Duas fontes de prescrição menos clássicas foram identificadas no discurso dos trabalhadores de duas zonas distintas.

O pecuarista, que vende a boiada para a empresa, fica presente fisicamente próximo aos postos de limpeza do filé, carimbo do lote e balança. Sua presença visa a teoricamente monitorar a boiada para a verificação de doenças ou irregularidades, mas também ao controle do peso final das carcaças e, consequentemente, do preço total do lote (E1, AL). "É porque dependendo da marcação, é determinado o preço - é o preço que eles recebem aqui. Quando está machucado eu tenho que marcar, e o preço da arroba do boi diminui" (T12, E1, AL). Na realidade, o pecuarista aparece como uma fonte de prescrição informal do trabalho dessa zona, indicando quando eles devem parar de cortar a peça (para que o boi pese mais, por exemplo) ou ainda orientando a classificação da boiada durante a fase de carimbo do lote. "Eu sou cobrada porque eles não querem perder, nem eles, nem o gerente. Então sou cobrada dos dois lados. Se eu marco eles não gostam e eu tenho que marcar. É a minha função" (T12, E1, AL). Essa presença é vista 
pelos trabalhadores como uma fonte de pressão suplementar. Além do mais, vai contra a prescrição da empresa que exige que um máximo de gordura seja eliminada durante a limpeza do filé, por exemplo. Os trabalhadores se encontram assim face a prescrições contraditórias."Ele cuida do pessoal para que retire apenas o sebo, não tire a carne. Às vezes pode tirar um pedaço de carne e eles não gostam” (T14, E1, AL). "Tem dias que eles até ameaçam a gente. Se mexer de novo eu dou um tiro" (T13, E1, AL).

Uma empresa de curtume, que compra o couro do boi da empresa do frigorífico, representa uma fonte de prescrição para os trabalhadores que retiram o couro do boi na área suja (E2, AS). Com efeito, a empresa de curtume paga uma gratificação mensal a esses trabalhadores para que eles efetuem a retirada do couro com um alto padrão de qualidade, quer dizer, sem furos nem marcações (que eles chamam de arraia). Em caso de não respeito às demandas de qualidade, a gratificação é anulada. "O curtume paga mais, por exemplo, 160 reais para cada um da linha para eles capricharem, para não cortar e nem para riscar. Eles dão um agrado por mês. Se der muita arraia e furo, eles já não pagam. Eles falam: 'Olha, pessoal, deu 10\% aí, falhou"' (T3, E2, AS). O contrato informal é de conhecimento dos trabalhadores de outras áreas, que consideram que a pressão está presente. "Aí é a pressão entre eles, né? Porque se um começa a cortar errado sobra para os outros também” (T16, E2, AL).

\section{Trabalho coletivo: "é uma equipe. Se um errar desanda tudo"}

O trabalho coletivo aparece no discurso dos trabalhadores como um fator determinante para a qualidade da produção. São ações realizadas em cadeia como previsto na organização do trabalho do tipo linha de produção. Os trabalhadores reconhecem o saber-fazer entre eles, e podem inclusive identificar se um trabalhador está sendo substituído por outro menos experiente ou se está utilizando uma ferramenta de má qualidade. "Se eu for no banheiro e ele for no meu lugar, ele vai no meu lugar porque o chefe pediu para ele ir, mas às vezes ele vai serrar a bucha, às vezes ele nem corta direito, aí o 'galo' já reclama porque faltou um pedacinho sem serrar" (T1, E4, AS). O encarregado de produção também sabe identificar a origem dos erros de acordo com a zona trabalhada. "Onde estiver o erro ele já sabe quem fez: igual à parte suja, a parte suja é a sola do boi, por exemplo, se vê uma contaminação já sabe que é lá do couro que veio” (T8, E4, AL).

Dependendo da região da carcaça que está sendo cortada, o impacto da ação de um trabalhador vai repercutir no posto seguinte ou três, quatro postos mais adiante. "Tem que chegar no final já pronto, sem nenhum hematoma, sem vacina. Aquela vacina no pescoço, umas inflamam para dentro e umas inflamam para fora e ficam entre a carne e o couro. Aqui fora dá para tirar, mas quando inflama mais para dentro fica mais difícil, porque a plataforma é um pouquinho alta, se ela estiver mais para cima, ele [o colega] não vai enxergar. Aí o pessoal lá da frente fica cobrando: 'Oh, tá passando vacina', mas estou tirando, passou porque não vi” (T6, E2, AS).

Sem o feedback do coletivo, nem todos os trabalhadores têm consciência do posto que arcará com as consequências de suas ações, sejam elas positivas ou negativas. As consequências positivas se manifestam como uma facilitação do trabalho, favorecendo um fluxo regular da linha de produção. Essas são menos evidenciadas. As consequências negativas, inversamente, são vividas como um trabalho adicional (dever de recuperação das falhas do processo) e como um fator de redução do tempo de realização da tarefa em curso. "Quando um não vem, o cara que vai no meu lugar prejudica esse aqui, o E, e o 'galo' e o serrador. Quatro. Aquele serrador de carcaça também é prejudicado. Porque se não serrar bem aqui, na hora que serrar a carcaça sai torto. Tem que serrar com serrote porque aquela serra lá não desce" (T1, E4, AS). A discussão em grupo diante do filme da atividade permitiu uma tomada de consciência por parte do trabalhador que serra o peito do boi em relação aos colegas que cortam a cabeça e o esôfago:

"Você pode ver que o esôfago fica solto lá. Essa tirinha vermelha é o esôfago para ele [E, E4, AL], porque se eu não soltar e ele for cheio, e ele puxar, cai tudo" (T8, E4, AL).

"Então se eu cortar errado prejudica vocês três" (T1, E4, AS).

"Prejudica!" (T8, E4, AL).

“Rapaz, eu não sabia não!” (T1, E4, AS).

Além do impacto na produção, um grupo de trabalhadores (E2) relatou que o trabalho coletivo terá igualmente um impacto na gratificação dos trabalhadores da área suja. Como visto anteriormente, a empresa de curtume paga uma gratificação em face da melhor qualidade do couro. Os trabalhadores dessa área são exigentes quanto ao trabalho realizado pelos colegas e aceitam com dificuldade a presença de profissionais novatos ou inexperientes nesses postos. "Acontece igual isso aí que estou falando 
para você, de errar quando troca de posição. Quando já esta todo mundo ocupando seu lugar, aí vai embora. Quando falta um, dá férias, daí troca, então vai, mas ele não tem a habilidade que o outro tem” (T3, E2, AS). "Se um errar todo mundo paga, mas se nós já sabemos quem está errado, nós já falamos: Oh, corta você aí, sai" (T6, E2, AS).

\section{Discussão}

Os resultados apresentados neste artigo corroboram resultados de algumas pesquisas já realizadas no setor, que evidenciam a presença de determinantes ligados à empresa conduzindo a efeitos negativos na saúde dos trabalhadores 5,6,8,13,28. Identificamos que a redução da produção (600 bois ao invés de 850) não diminuiu a intensificação do trabalho (quantidade de bois por hora), pois a escolha da empresa foi de manter o ritmo da nória e não de reduzi-lo. Os trabalhadores parecem naturalizar essa intensificação, falando em "preferência” por um ritmo mais acelerado que permitiria vencer a monotonia e obter mais tempo de recuperação do cansaço (embora saibamos que os riscos de LER/ DORT aumentam neste caso). Essa situação revela uma contradição do sistema da atividade 29 e fornece perspectivas para investigações mais detalhadas.

Dados novos aparecem na presente pesquisa, referentes às fontes de prescrição heterogêneas do trabalho, que impactam a atividade individual e coletiva. Por um lado, a presença do pecuarista na área limpa e suas injunções constituem uma fonte de prescrição contraditória à da empresa. Os trabalhadores vivem esse fato como uma pressão suplementar aos constrangimentos do trabalho. Por outro lado, a gratificação paga pelo curtume constitui uma prescrição da qualidade do trabalho na área suja, representando uma pressão não somente na atividade individual, mas também no coletivo de trabalho. Por coletivo de trabalho entendemos, como Clot 25, o que vai além do trabalho coletivo (divisão e organização das tarefas), como as regras de ofício, o reconhecimento e a confiança mútua. Esses elementos constituem uma parte importante da saúde no trabalho como evidenciado em várias pesquisas nas ciências do trabalho. De acordo com Laigle \& Mardaga 30, esse tipo de contrapartida financeira beneficia, em primeiro lugar, a empresa, e em segundo os trabalhadores (ainda) sadios, sem que nenhuma garantia seja dada quanto aos riscos em longo prazo.

Com base nos resultados, e corroborando estudos internacionais, além das dimensões físicas do trabalho, aspetos organizacionais, humanos e estratégicos devem ser considerados em projetos de rodízio de postos. O projeto em questão apresenta-se como uma oportunidade de questionar as escolhas organizacionais da empresa que impactam a saúde dos trabalhadores. As ingerências observadas, o material defeituoso ou o ritmo acelerado constituirão objetos de debate e de negociação no âmbito do comitê de ergonomia. A próxima etapa do projeto consiste em constituir grupos de trabalho com trabalhadores das duas zonas do abate, a fim de construírem juntos e formalizar os critérios ergonômicos do rodízio e simular a organização da rotação (postos, duração, frequência etc.). Espera-se que os resultados finais permitam um retorno de experiência com relação à NR-36.

\section{Colaboradores}

A. Nascimento contribuiu com a coleta e tratamento de dados e redação do artigo. I. A. Messias contribuiu com a coleta de dados e redação do artigo.

\section{Agradecimentos}

A pesquisa foi possibilitada graças ao programa Cátedras Franco-Brasileiras no Estado de São Paulo. Aos trabalhadores que participaram do estudo, assim como à empresa que realizou a demanda. 


\section{Referências}

1. Associação Brasileira das Indústrias Exportadoras de Carne. Sumário/2018 - perfil da pecuária no Brasil. http://www.abiec.com.br/ (acessado em 03/Set/2018).

2. Santana NI, Rodrigues GRS. Acidentes do trabalho em frigofiricos. Cientefico 2014; 14:75-96.

3. Gonçalves DD, Teles PS, Reis CR, Lopes FMR, Freire RL, Navarro IT, et al. Seroepidemiology and occupational and environmental variables for leptospirosis, brucellosis and toxoplasmosis in slaughterhouse workers in the Paraná State, Brazil. Rev Inst Med Trop São Paulo 2006; 48:135-40.

4. Vasconcellos MC, Pignatti MG, Pignati WA. Emprego e acidentes de trabalho na indústria frigorífica em áreas de expansão do agronegócio, Mato Grosso, Brasil. Saúde Soc 2009; 18:662-72.

5. Coutarel F, Dugué B, Daniellou F. Interroger l'organisation du travail au regard des marges de manoeuvre en conception et en fonctionnement. La rotation est-elle une solution aux TMS? PISTES 2003; 5:1-28.

6. Richard P. Analyse ergonomique et mesures biomécaniques dans un abattoir de porcs. PISTES 2002; 4:1-14.

7. Ouellet S. Contribution de l'ergonomie à la conception d'un outil de formation. Activités 2002; 10:3-19.

8. Vogel K, Karltun J, Eklund J, Engkvist IL. Improving meat cutter's work: changes and effects following an intervention. Appl Ergon 2013; 44:996-1003.

9. Johnson ES. Cancer mortality in workers employed in cattle, pigs, and sheep slaughtering and processing plants. Environ Int 2011; 37:950-9.

10. Procuradoria Regional do Trabalho da 12a Região, Ministério Público do Trabalho de Santa Catarina. Invigilando. http:/www.prt12.mpt. mp.br/ (acessado em 03/Jun/2017).

11. Ministério do Trabalho e Emprego. Portaria no 555, de 18 de abril de 2013. Aprova a Norma Regulamentadora no 36 - Segurança e Saúde no Trabalho em Empresas de Abate e Processamento de Carnes e Derivados. Diário Oficial da União 2013; 19 abr.

12. Ouellet S, Vézina N, Malo JL, Chartrand J. L'implantation de la rotation de postes: un exemple de démarche préalable. PISTES 2003; $5: 1-25$.

13. Falardeau A, Vézina N. Rotation des postes, assignation temporaire et impact des absences dans une usine d'abattage et de transformation du porc. PISTES 2002; 4:1-28.

14. Barth DC, Guimarães LBM. Análise do impacto do rodízio no grau de risco postural e de desconforto/dor de trabalhadores na desossa de frango. In: Anais do 14o Congresso Brasileiro de Ergonomia. Porto Seguro: Associação Brasileira de Ergonomia; 2008
15. Frazer MB, Norman RW, Wells RP, Neumann WP. The effects of job rotation on the risk of reporting lowback pain. Ergonomics 2003; 46:904-19.

16. Wyatt R, Davison C, Rickman F, Clampitt D. Overcoming traditional job rotation obstacles in the design of a manufacturing cell. In: Alexander DC, Rabourn RA, editors. Applied ergonomics. London: Taylor \& Francis 2001. p. $76-81$

17. Coutarel F, Daniellou F, Dugué B. Conception et organisation du travail dans les abattoirs en France: la polyvalence est-elle une solution aux TMS? In: Les Actes du Forum d'Échange de la Chaire GM en Ergonomie. Montréal: Univeristé du Québec; 2003. p. 109-15.

18. Chatigny C, Vézina N, Prévost J. Formation et soutien à l'apprentissage: des conditions indispensables à la polyvalence et à la santé et sécurité au travail. PISTES 2003; 5:1-26.

19. Neiva F, Silva IMS. Vantagens e desvantagens da rotação de postos de trabalho: a visão dos trabalhadores e das chefias. In: Araújo M, Martins D, organizadores. Investigação e intervenção em recursos humanos - gestão para a cidadania. Porto: Instituto Politécnico do Porto/ Edições Politema; 2012. p. 597-608.

20. Almeida R. A Ergonomia sob a ótica francesa e sob a ótica anglo-saxônica. Vértices 2011; 13:115-26.

21. Falzon P, Teiger C. Construire l'activité. Performances Humaines et Techniques 1995; no hors-série (Septembre):34-40.

22. Falzon P, organizador. Ergonomia construtiva São Paulo: Editora Blücher; 2016.

23. Morgan DL. Focus group. Annu Rev Sociol 1996; 22:129-52.

24. Silva IS, Veloso AL, Keating JB. Focus group: considerações teóricas e metodológicas. Revista Lusófona de Educação 2014; 26:175-90.

25. Clot Y. La fonction psychologique du travail. Paris: PUF; 1999. (Coll. Travail Humain).

26. Mollo V, Nascimento A. Práticas reflexivas e desenvolvimento dos indivíduos, dos coletivos e das organizações. In: Falzon P, organizador. Ergonomia construtiva. São Paulo: Editora Blücher; 2016. p. 283-303.

27. Fontanella BJB, Luchesi BM, Saidel MGB, Ricas J, Turato ER, Melo DG. Amostragem em pesquisas qualitativas: proposta de procedimentos para constatar saturação teórica. Cad Saúde Pública 2011; 27:389-94.

28. Vilela RAG, Almeida IM, Mendes RWB. Da vigilância para prevenção de acidentes de trabalho:contribuição da ergonomia da atividade. Ciênc Saúde Coletiva 2012; 17:2817-30.

29. Engeström Y. Activity theory as a framework for analyzing and redesigning work. Ergonomics 2000; 43:960-74.

30. Laigle F, Madarga J. De l'évaluation des facteurs de risque et causes de TMS aux tentatives de maintien dans leur activité des ripeurs (chargeurs). In: 41ème Congrès de la SELF. Caen: Société d'Ergonomie de Langue Française; 2006. p. 315-9. 


\section{Abstract}

Brazilian Regulation NR-36, specific to the slaughterhouse and meat packing industries, emphasizes the implementation of job turnover to reduce workers' exposure to repetitive and machinecontrolled physical strain. However, studies have shown that the effects of such measures are generally less than expected, and that rotation alone is not the solution to work-related health problems. Based on a study performed in a beef packing plant, the article aims to present and discuss real work dimensions that are considered relevant to the plant workers' health and safety. Knowledge of such dimensions is important for the implementation of job rotation projects. The methodology included interviews with 16 volunteers divided into four groups. The focus group and collective confrontation techniques were used, drawing on videos of the work. The results pointed to dimensions already known in the literature, related to physical strain, the required skills, work pace, and insufficient time to perform quality work. New data appeared in relation to the work's heterogeneous specifications, representing a source of psychological pressure during work in the cattle slaughtering areas. These organizational dimensions impact workers' individual and collective activity as well as workplace health. In our view, and corroborating international studies, in addition to the work's physical dimensions, organizational, human, strategic, and pedagogical aspects should be considered in projects involving the implementation of job rotation.

Abattoirs; Workload; Labor Legislation; Occupational Health

\section{Resumen}

La norma brasileña NR-36, específica para industrias de sacrificio y procesamiento de carnes, indica la necesidad de la implantación de rotación de puestos para reducir la exposición de los trabajadores a presiones físicas repetitivas y controladas por máquinas. No obstante, algunos estudios demuestran que los efectos alcanzados con esa implantación son generalmente inferiores a lo esperado, y que sólo la rotación no sería la solución para los problemas de salud en el trabajo. Mediante una investigación empírica en un frigorífico de sacrificio de bovinos, el objetivo de este artículo es presentar y discutir las dimensiones del trabajo real, consideradas relevantes para la salud y seguridad de los trabajadores. Tales dimensiones constituyen elementos importantes que deben ser consideradas en proyectos de implantación de rotación de puestos. La metodología comprende entrevistas colectivas con 16 trabajadores voluntarios divididos en 4 grupos. Se utilizaron técnicas de grupos focales y confrontación colectiva, valiéndose de grabaciones de la actividad. Los resultados evidencian dimensiones y a conocidas en la literatura, relacionadas con presiones físicas, competencias necesarias, ritmo de trabajo y falta de tiempo para realizar un trabajo de calidad. Aparecen nuevos datos en relación con las prescripciones heterogéneas del trabajo que representan una fuente de presión psíquica en zonas de sacrificio. Estas dimensiones organizativas impactan en la actividad individual y colectiva de los trabajadores, así como la salud en el trabajo. Desde nuestro punto de vista, y corroborando estudios internacionales, además de las dimensiones físicas del trabajo, se deben considerar aspectos organizativos, humanos, estratégicos y pedagógicos en proyectos de implantación de rotación de puestos.

Mataderos; Carga de Trabajo; Legislación

Laboral; Salud Laboral
Recebido em 05/Jun/2017

Versão final reapresentada em 22/Mar/2018

Aprovado em 30/Mai/2018 